\title{
Digital Rx: Obama pushing for paperless prescriptions
}

$\mathrm{T}$

he United States government is telling doctors it's time to set aside their legendarily lousy handwriting and convert to electronic prescriptions. To drive home the point, it's rewarding those who switch now, penalizing those who wait and taking stronger steps to keep digital snoops from seeing people's health secrets.

Few corners of the largely private, partly public and hugely complicated US health care system offer magicbullet solutions to soaring costs and patchwork care.

E-prescribing, to hear advocates tell it, may be one.

"We've got the most inefficient health care system imaginable," President Barack Obama told a news conference in one of his frequent pitches on the subject. "We're still using paper. We're still filing things in triplicate. Nurses can't read the prescriptions that doctors have written out."

"Why wouldn't we want to put that on an electronic medical record that will reduce error rates, reduce our longterm costs of health care?"

Physicians are picking up the pace of conversion, although they have a long way to go. Only about $12 \%$ of doctors' offices use paperless prescriptions, according to the latest estimates.

But the ranks doubled last year and are swelling at an even faster rate now, thanks to a variety of enticements and a new US\$19-billion effort by Obama to promote digital record-keeping throughout medicine.

Doctors surveyed last year by the American Medical Association reported a variety of benefits from e-prescribing, the main one being improved accuracy. That's no small matter in a country where more than 1.5 million people a year are hurt by medication mistakes such as wrong doses, missed histories of drug interactions and misread prescriptions. The doctors also cited improved office productivity and convenience.

Among the downsides they identified: higher upfront costs than ex-

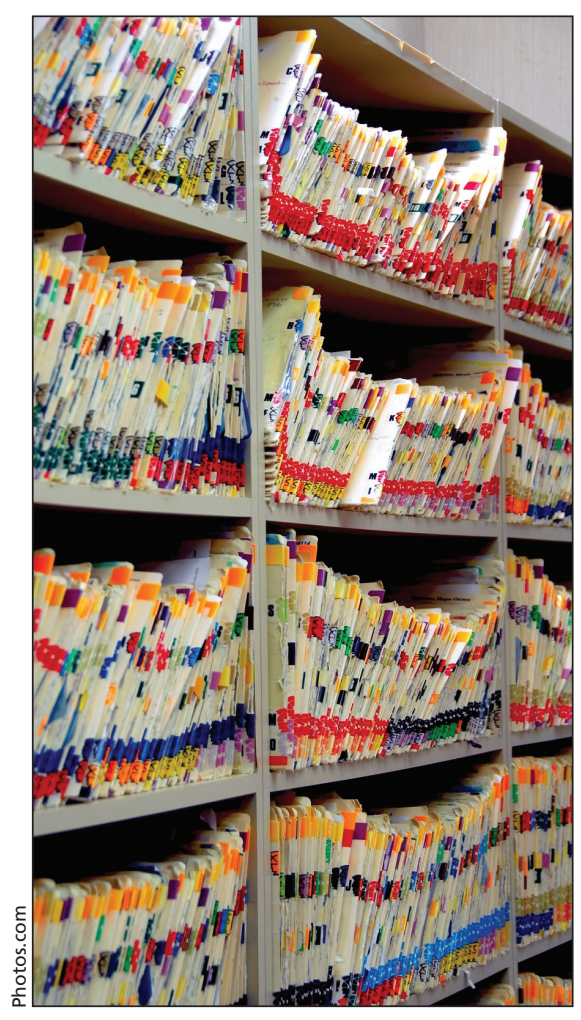

Proponents believe e-prescribing will reduce paperwork and health care system costs.

pected, glitches in digitizing existing files and lagging technology in pharmacies still struggling to get with the program.

Even so, holdouts are coming aboard.

The primary carrot from the feds is a $2 \%$ bonus in reimbursement rates for doctors who perform services under Medicare, the public health insurance and drug program for the elderly and disabled.

That bonus could be worth US\$1500 a year, helping to cover costs as high as US\$3000 per doctor for setting up paperless prescriptions.

In 2012, that carrot turns to a stick as Medicare payments are cut to doctors still immersed in paper.

In essence, e-prescribing means the doctor fills out a prescription authorization on a computer and sends it digi- tally to a pharmacy. Computer printouts hand delivered by patients or faxed by physicians don't count.

A thorough e-prescription program is designed to do even more. Alerts pop up if a dose looks questionable - a bit of insurance if, say, the doctor's keyboard skills are no better than his penmanship. The program can flag drug or allergy histories that the doctor might not have been told about.

Moreover, electronic integration with patients' drug plans tells doctors what the copayments are for various medications. A recent study examined 17.4 million prescriptions filed over 18 months and found that e-prescribing zeroed in on cheaper medications at a rate that could save US\$845 000 per 100000 patients (Arch Intern Med 2008;168[22]:2433-9). "Higher levels of e-prescribing use would increase these savings," the authors stated.

All told, e-prescribing can round up a wealth of information. But it's deeply personal information that people don't willingly share with neighbours, much less the digital universe.

Privacy watchdogs fear that marketers, potential employers, credit companies and unscrupulous operators would feast on health records without stronger safeguards. They've been largely mollified by a new law, which bans the sale of protected health information and sets up a regimen of encryption, audit trails, breach notifications and multiple layers of enforcement.

Still, everyone knows that snoops are cunning and authorized users can be clumsy.

When a huge drug store chain throws labelled pill bottles and IDpacked patient forms in back-alley dumpsters for any scavenger to see, as was alleged to have happened in a case settled with the government in February, it's easy to imagine lapses occuring higher up the technology ladder. Cal Woodward, Washington, DC

DOI:10.1503/cmaj.090445 